\title{
ATLAS SOCIOECONÔMICO DO RIO GRANDE DO SUL: QUINZE ANOS ACOMPANHANDO AS TRANSFORMAÇÕESDO ESTADO
}

\author{
SOCIO-ECONOMIC ATLAS OF RIO GRANDE DO SUL STATE: \\ FIFTEEN YEARS MONITORING STATE'S TRANSFORMATIONS
}

\author{
Antonio Paulo Cargnin \\ Doutor em Geografia \\ Secretaria do Planejamento, Gestão e Participação Cidadã (SEPLAG/RS) \\ acargnin@seplag.rs.gov.br \\ Ana Maria de AvelineBertê \\ Mestre em Geografia \\ SEPLAG/RS \\ aberte@seplag.rs.gov.br \\ Bruno de Oliveira Lemos \\ ,Mestre em Geografia \\ SEPLAG/RS \\ bruno-lemos@seplag.rs.gov.br \\ Suzana Beatriz de Oliveira \\ Especialista em Geografia Ambiental \\ SEPLAG/RS \\ soliveira@seplag.rs.gov.br
}

\section{Resumo:}

Este artigo tem por finalidade resgatar o processo de construção do Atlas Socioeconômico e, também, abordar algumas transformações ocorridas na economia e sociedade gaúcha que podem ser identificadas pela trajetória da publicação nos quinze anos de existência. Inicialmente é realizado um histórico sobre a elaboração do Atlas e são apresentados elementos metodológicos que caracterizaram as diferentes edições. Em um segundo momento foram abordados temas que sinalizam para as transformações ocorridas na economia e a sociedade gaúcha nesses quinze anos. Seguem as considerações finais e as referências utilizadas.

Palavras chave: Planejamento territorial; Atlas Socioeconômico; Rio Grande do Sul

\begin{abstract}
:
This article aims at recovering the building process of the Socioeconomic Atlas, as well as addressing some transformations undergone by State economy and society that may be identified in the fifteen-year trajectory of the publication. Initially a background on the Atlas development is made, and methodological elements that characterized the different editions are presented. In a second moment, it was made an approach of the themes that point to the changes occurred in the State economy and society along these fifteen years. Following come the closing remark sand references used.
\end{abstract}

Key-words: Territorial planning; Socio-Economic Atlas; Rio Grande do Sul State 


\section{Introdução}

O ano de 2013 marca os quinze anos de uma iniciativa pioneira desenvolvida junto a Secretaria do Planejamento, Gestão e Participação Cidadã do Estado do Rio Grande do Sul (SEPLAG/RS): o lançamento do Atlas Socioeconômico do Rio Grande do Sul. Em meio a um contexto repleto de descontinuidades a publicação tem se mantido como uma importante referência para os órgãos públicos na formulação de políticas, estudantes dos diferentes níveis de ensino, pesquisadores e demais atores que buscam informações sobre o Estado gaúcho.

O Atlas Socioeconômico registrou nesses quinze anos importantes transformações econômicas, demográficas e sociais, que oferecem subsídios para a compreensão da situação atual do Estado. Alterações na matriz econômica, na pauta de exportações, mudanças no perfil demográfico e a evolução dos indicadores de saúde e educação, são exemplos de mudanças registradas nas páginas da publicação.

A publicação também evoluiu do ponto de vista de sua metodologia e a mudança do para o meio digital facilitou o acesso e a disseminação das informações. Contudo, o Atlas tem mantido sua característica principal de oferecer uma síntese socioeconômica, contendo os elementos essenciais para uma primeira aproximação no sentido de compreender a realidade gaúcha. As informações são apresentadas prioritariamente através de mapas e, de forma complementar, de gráficos e tabelas, sempre acompanhadas de análises das diferentes temáticas abordadas.

Este artigo tem por finalidade resgatar o histórico da construção das diferentes edições do Atlas Socioeconômico e, também, mostrar algumas transformações ocorridas na economia e sociedade gaúcha nesses quinze anos. Inicialmente, são apresentadas especificidades sobre a construção das diferentes edições e elementos metodológicos que as caracterizaram. Em um segundo momento, foram abordados alguns aspectos que sinalizam para as transformações ocorridas na economia e a sociedade gaúcha nesses quinze anos. Por último, são apresentadas considerações sobre a publicação e as transformações ocorridas nesses quinze anos.

\section{As diferentes edições e seus aspectos metodológicos}

A elaboração da primeira edição do Atlas foi publicada no ano de 1998 tendo sua origem vinculada à construção de uma síntese geográfica que possibilitasse apresentar o Estado do Rio Grande do Sul em seus principais aspectos 
socioeconômicos, tanto do ponto de vista de sua dinâmica interna com base nos seus municípios quanto de sua dinâmica externa, através da comparação com as demais unidades da federação, Brasil e países selecionados. O projeto inicial teve como referência o Atlas Économic et Social de La RégionRhôneAlphes, trazido para o Estado depois de missão internacional cumprida pelo então Secretário da Pasta João Carlos Brum Torres.

A primeira edição do Atlas teve seu início no ano de 1996, tendo sido elaborada por um grupo multidisciplinar coordenado pelos geógrafos que atuavam junto ao Departamento de Desenvolvimento Regional e Urbano (DDRU) da então Secretaria da Coordenação e Planejamento(SCP). Participaram da elaboração os Geógrafos Antonio Paulo Cargnin e Silvia Maria Berwanger Profes, a pedagoga Ana Pujol Vieira dos Santos e os economistas Antonio Carlos Coutinho Fraquelli e Pedro Silveira Bandeira (RIO GRANDE DO SUL/SCP, 1998).

A não existência de uma estrutura de Sistema de Informações Geográficas na Secretaria ocasionou que os mapas temáticos dessa edição fossem produzidos de forma conjunta com a empresa gerenciadora do Programa para o Desenvolvimento Socioambiental da Região Hidrográfica do Guaíba (PRÓ-GUAÍBA). Atuaram na elaboração do Atlas pela empresa os técnicos Cláudio Ruschel, Eloísa S. de Moraes, Íria M. Garaffa e Lígia M. Pinto.OAtlas foi finalizado no ano de 1998, tendo sido lançado na $44^{\mathrm{a}}$ Feira do Livro de Porto Alegre. A publicação foi estruturada em cinco capítulos iniciando-se por uma apresentação sobre as características gerais do Estado e tendo continuidade pelas áreas de infraestrutura, população, condições de vida e economia. Nessa edição foram utilizadas diversas fontes de dados, com destaque para os dados da Contagem Populacional de 1996 realizada pelo Instituto Brasileiro de Geografia e Estatística (IBGE), da Fundação de Economia e Estatística (FEE) e dos dados obtidos diretamente dos diversos órgãos do Estado.

A partir do ano 2000 foi iniciado o projeto para a publicação da segunda edição do Atlas, também lançada de modo impresso no ano de 2002. Nessa edição todo o trabalho passou a ser elaborado e executado pela equipe de geógrafos que atuavam junto ao DDRU. A equipe técnica era formada pelos Geógrafos Antonio Paulo Cargnin, Ana Maria de Aveline Bertê, Herbert Klarmann, Sílvia Maria Berwanger Profes e Suzana Beatriz de Oliveira.O grupo ficou responsável pela elaboração do projeto, pela seleção 
dos temas, coleta e analises de dados, elaboração dos textos e realização da cartografia, já em meio digital. A publicação manteve a característica de apresentar através de mapas temáticos, gráficos e tabelas dados organizados em diferentes escalas e, além disso, ampliou a abordagem com a inserção de novos temas e análises mais detalhadas. Assim, a segunda edição foi estruturada em seis capítulos, iniciando-se por uma apresentação onde foram descritas as características gerais do Estado. Seguiram-se o tema do meio ambiente, infraestrutura, população, indicadores sociais e economia(RIO GRANDE DO SUL/SCP, 2002).

Os mapas foram gerados a partir da base cartográfica digital 1:1.000.000 e disponibilizados em diversas escalas para impressão, em Projeção Policônica utilizando o Sistema Horizontal de Referência WGS 1984. A partir dessa edição a cartografia digital foi realizada, predominantemente, com a utilização de softwares da família ArcGis, utilizando diversos níveis de agrupamento das informações geográficas.

A partir do ano de 2003, o Atlas passou a ser totalmente elaborado em formato digital, conservando o mesmo layout da edição impressa, e disponibilizado na sua íntegra em link próprio na página da SEPLAG/RS como um produto permanente daquela instituição ${ }^{1}$. Desde então, passou a ser mantido e atualizado pelo grupo técnico que atua junto ao Departamento de Planejamento Governamental (DEPLAN) da Secretaria.Atualmente o grupo é formado pelos Geógrafos Antonio Paulo Cargnin, Ana Maria de Aveline Bertê, Bruno de Oliveira Lemos e Suzana Beatriz de Oliveira. Também atuou no grupo entre os anos de 2010 e 2013 a Analista de Planejamento, Orçamento e Gestão Laurie Fofonka Cunha² .

Os temas tratados vêm sendo ampliados e as informações atualizadas na medida em que novos dados são divulgados. Em 2013,o site e o layout foram remodelados e modernizados, com o propósito de manter a atualidade da publicação, facilitar o acesso dos usuários e, principalmente, aprofundar as análises existentes.A publicação utiliza diversas bases geográficas, sendo a base municipal com 496 municípios (2003) a mais empregada. Também foram utilizadas as bases de 333 municípios (1991), 427 municípios (1992), 467 municípios (1995) e497 municípios

\footnotetext{
${ }^{1} \mathrm{O}$ Atlas está disponível no link www.seplag.rs.gov.br/atlas.

${ }^{2}$ Desde a primeira edição do Atlas contribuíram como estagiários Gisele Banda de Magalhães, Anderson de Jesus Nunes, Iara Rejane Gross, Eduardo Marques Martins e Lucas Stanislawski Silva.
} 
(2013). As divisões regionais mais utilizadas foram a dos Conselhos Regionais de Desenvolvimento (COREDEs) e a das Regiões Funcionais de Planejamento. Os dados são obtidos dos bancos públicos implementados por diferentes instituições, com destaque para o IBGE, a FEE, o Instituto Nacional de Estudos e Pesquisas Educacionais Anísio Teixeira (INEP) e o Banco de dados do Ministério da Saúde - DATASUS.

\section{Mudanças no perfil demográfico gaúcho no período 1998 - 2013}

O perfil demográfico da população do Estado do Rio Grande do Sul apresentou significativas alterações nas últimas décadas em seus diferentes aspectos. Algumas dessas mudanças podem ser constatadas nas edições dos quinze anos do Atlas Socioeconômico do RS e seus impactos extrapolam a análise demográfica e exercem influências sobre a economia e a sociedade gaúcha. Exemplos nesse sentido podem ser observados por meio da análise de características da população como o ritmo do crescimento populacional, as alterações do perfil da fecundidade, a distribuição da população de acordo com a situação de domicílio e as alterações na estrutura populacional por faixa etária e gênero ${ }^{3}$.

Nos últimos quinze anos a população total do Rio Grande do Sul, cresceu em 1,1 milhão de habitantes, passando de 9,6 milhões para 10,7 milhões. Considerando os dados dos últimos Censos Demográficos, a taxa de crescimento anual no Estado no período 1991 a 2000 foi de 1,21\% e no período 2000-2010 de 0,49\%, valor bem inferior ao da década anterior e a menor taxa entre os estados brasileiros. Se levarmos em consideração que no início do século XX o Estado chegou a apresentar valores em torno de 3\%, estes números são bastante baixos. Esse fenômeno não é recente, já que, desde 1960, a taxa de crescimento demográfico do Estado e do País vem diminuindo gradativamente, conforme apresentado no Figura 1, seguindo a tendência já observada em países que já alcançaram a transição demográfica ${ }^{4}$.

\footnotetext{
${ }^{3}$ Foram utilizados dados dos Censos Demográficos do Instituto Brasileiro de Geografia e Estatística (IBGE) de 1991, 2000, 2010, da Contagem Populacional de 1996 e das Projeções da Fundação de Economia e Estatística (FEE) para 2030.

${ }^{4}$ A transição demográfica pode ser entendida como um padrão de mudanças no comportamento do
crescimento populacional e na sua estrutura etária, fruto, principalmente, de um processo de redução em
seus níveis de fecundidade e mortalidade. Como resultado, em um primeiro momento, presencia-se um
aumento das taxas de crescimento populacional (uma explosão demográfica), mas, com a queda da
natalidade, o ritmo de crescimento da população vai se reduzindo ao longo do tempo, tendendo para a
estabilidade, ou mesmo para a redução da população absoluta (BANDEIRA, 2010).
}

Geo UERJ - Ano 15, n' ${ }^{\circ}$ 24, v. 2, $2^{\circ}$ semestre de 2013

ISSN: 1415-7543 E-ISSN: 1981-9021

http://www.e-publicacoes.uerj.br/index.php/geouerj 
Figura 1 - Evolução da Taxa de Crescimento no Brasil e Rio Grande do Sul no período $1950-2010$

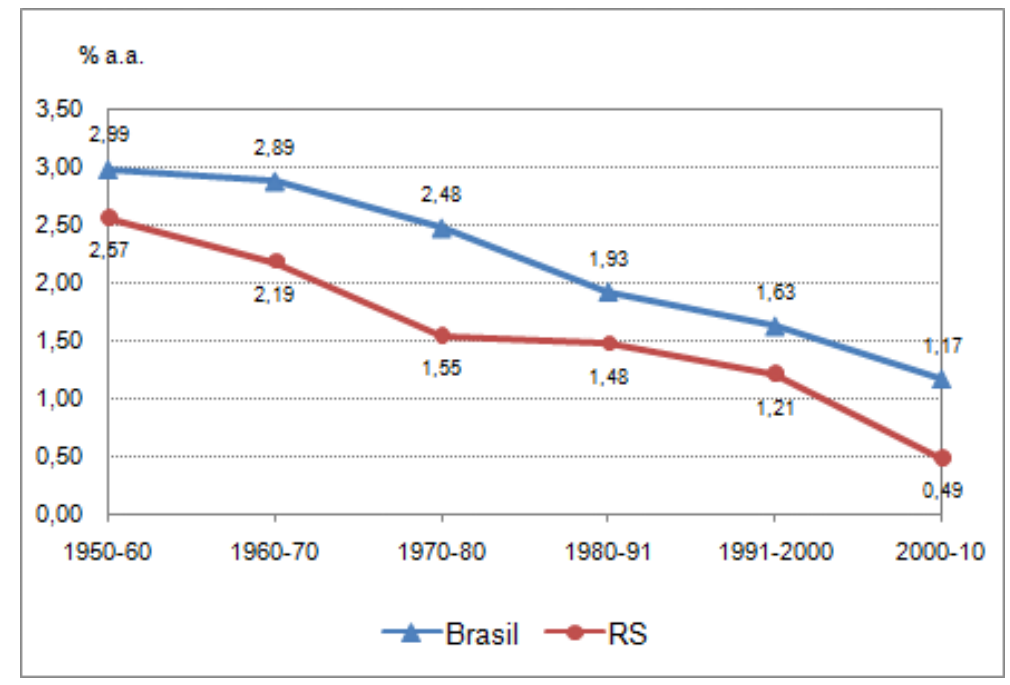

Fonte: IBGE

No Rio Grande do Sul as taxas de crescimento apresentam grande variabilidade. Mesmo com redução no ritmo de crescimento, há regiões no Estado que aumentaram significativamente sua população, como no caso da Serra e do Litoral que apresentaram crescimento bem acima da média estadual. Já os municípios de Xangri-lá (4,3\% a.a.), Arroio do Sal (3,9\% a.a.), Balneário Pinhal (3,8\% a.a.), Imbé (3,7\% a.a.), Capão da Canoa (3,3\% a.a.) e Tramandaí (3,0\% a.a.), estão entre os dez municípios com maior crescimento demográfico do Estado. O município de Caxias do Sul, na região da Serra, mesmo tendo apresentado crescimento menor que na década anterior, foi o que apresentou maior incremento absoluto de população, superando até mesmo a capital Porto Alegre e municípios da Região Metropolitana de Porto Alegre (RMPA).

Excetuando Pelotas, no sul do Estado, e Santa Maria, na região central, os municípios mais populosos do Estado ainda se localizam no eixo entre a RMPA e Caxias do Sul, confirmando a tendência já observada no final da década de 90, onde já encontrávamos nessa região a mais extensa área de continuidade urbana do Estado.

Por outro lado, pode ser observado um aumento das áreas que sofreram esvaziamento populacional. No primeiro período 1991-2000 os municípios que mais perderam população estavam localizados no norte do Estado. Os resultados do último Censo revelam queda geral no ritmo de crescimento e expansão desta tendência para o oeste e alguns pontos no sul, conforme pode ser observado nas Figuras 2 e 3. 
Figura 2 - Taxa de Crescimento da população no Rio Grande do sul, por município, no período 1991-2000

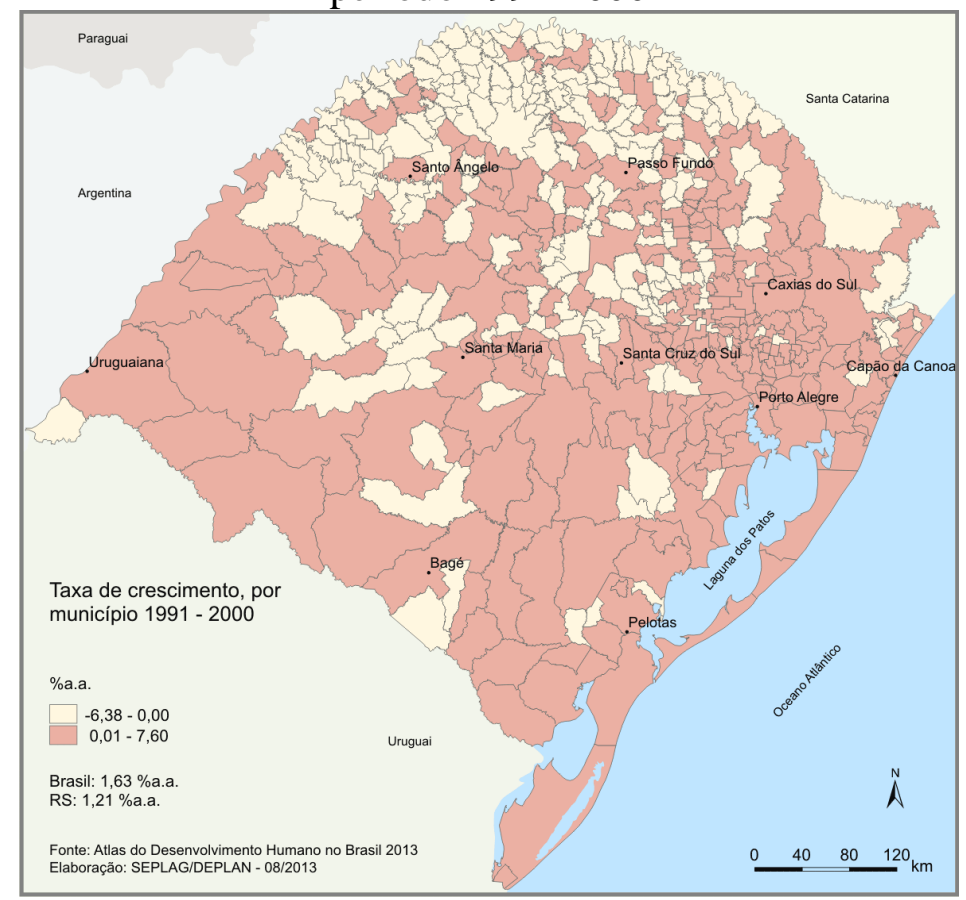

Figura 3 - Taxa de Crescimento da população no Rio Grande do sul, por município, no período 2000-2010

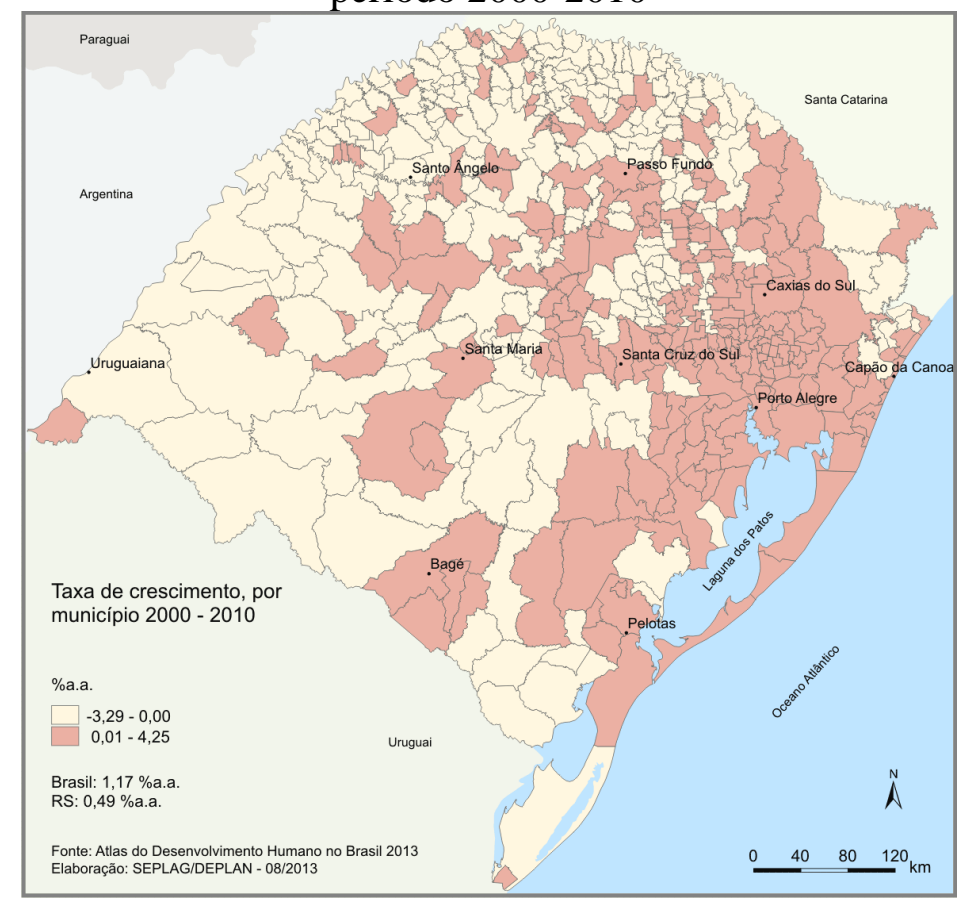

Um dos fatores preponderantes no processo que vem resultando no dramático decréscimo da população de grande número de municípios é a acentuada queda da taxa de fecundidade, que corresponde ao número médio de filhos que teria uma mulher de uma coorte hipotética (15 a 49 anos de idade) ao final do seu período reprodutivo. No 
Rio Grande do Sul em 1998, a média era de 2,1 filhos por mulher e, atualmente, conforme dados do censo demográfico de 2010, o número é de 1,8 filhos.

Ao analisarmos em um período mais longo observamos que a fecundidade já vinha em constante queda no Rio Grande do Sul, assim como no Brasil. Em 1960 a taxa de fecundidade no Estado era de 5,1 filhos por mulher. Desde então, a redução ocorreu de forma gradativa: $1970(4,3), 1980(3,1), 1991(2,4), 2000(2,2)$ até o valor mais recente de 1,8 filhos por mulher, como pode ser observado na Tabela 1. Esta média já está abaixo da taxa de reposição populacional e o declínio foi muito rápido se comparado ao experimentado pela Europa, por exemplo, onde esses valores levaram pelo menos 150 anos para atingir níveis semelhantes.

Tabela 1 - Taxa de Fecundidade no Brasil e Rio Grande do Sul, 1960 - 2010

\begin{tabular}{|ccc|}
\hline Ano & Brasil & Rio Grande do Sul \\
\hline 1960 & 6,28 & 5,11 \\
\hline 1970 & 5,76 & 4,29 \\
\hline 1980 & 4,35 & 3,11 \\
\hline 1991 & 2,85 & 2,39 \\
\hline 2000 & 2,38 & 2,17 \\
\hline 2010 & 1,90 & 1,75 \\
\hline
\end{tabular}

Fonte: IBGE

Entre os fatores que contribuem para a queda da fecundidade podem ser destacados o processo de urbanização como conseqüência do aumento da industrialização, o aumento no nível educacional, o acesso das mulheres ao mercado de trabalho, a disseminação de métodos contraceptivos e a melhora nas condições de saúde, entre outros, foram fundamentais para essa mudança.

Já a urbanização, nestes últimos vinte anos, embora em ritmo menos acelerado que nas décadas anteriores, manteve-se crescente no Estado. Em 1991 o percentual de população que residia no meio urbano era de 76,6\%, em 1996 este valor passou para $78,7 \%$, em 2000 para $81,7 \%$ e em 2010 já chega a 85,1\% dos gaúchos vivendo nas cidades, como pode ser verificado no Figura 4. Além disso, houve um aumento significativo de municípios que, seguindo as tendências, ampliaram suas taxas de urbanização nesse período.

A migração também é um componente que interfere no comportamento do crescimento populacional. O saldo migratório do Rio Grande do Sul tem sido negativo ao longo destes últimos anos, o que contribuiu, embora em menor peso, para a 
diminuição da intensidade nas taxas de crescimento. A perda de população absoluta por migração, principalmente para outros estados do Brasil, entre 1995-2000 foi de 39.495 habitantes e entre 2005-2010, quase dobrou, passando para 74.650 habitantes. Mesmo assim, o ritmo de crescimento da taxa líquida de emigração, ou seja, da proporção de naturais do Rio Grande do Sul residentes fora do Estado (não incluídos os residentes fora do país) em relação ao total da população natural do Estado, vem se mantendo constante nestes últimos vinte anos.

Figura 4 - Evolução da população Urbana e Rural no Rio grande do Sul, 1940 - 2010

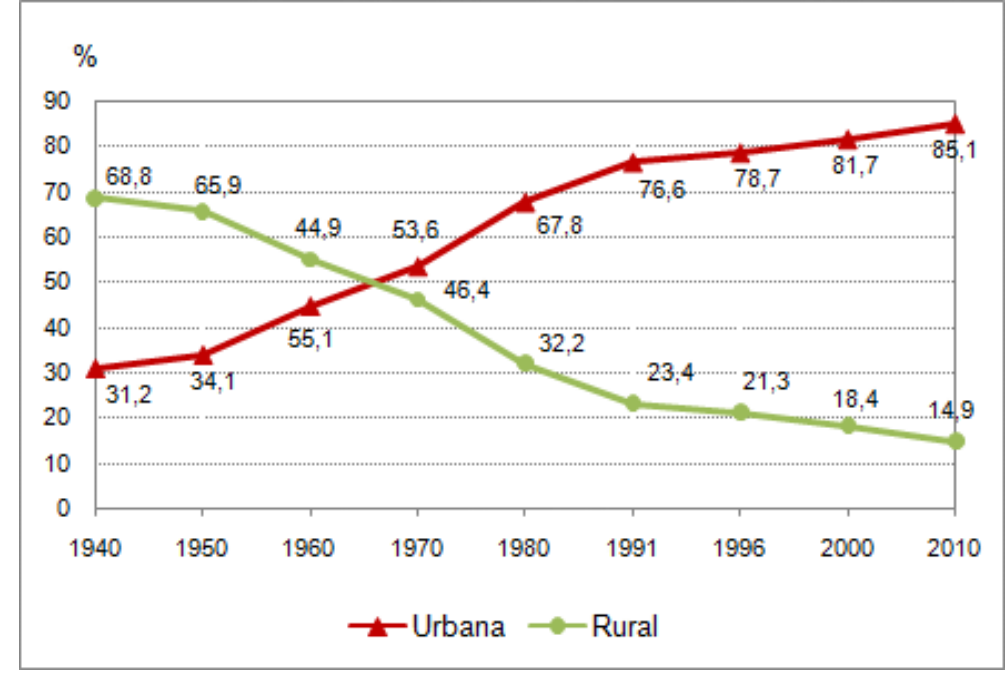

Fonte: IBGE

O declínio da taxa fecundidade, a queda da mortalidade e o aumento da expectativa de vida da população gaúcha afetaram diretamente a distribuição etária da população. Houve um estreitamento da base da pirâmide populacional em contraposição a um alargamento do topo, como pode ser observado nas pirâmides etárias representadas na Figura 5.Em 1991, a faixa mais larga da pirâmide etária correspondia ao intervalo entre 5 e 9 anos, em 2000 ficava entre 15 e 19 e, em 2010, entre 25 e 29 anos. Já o topo da pirâmide, correspondente à faixa acima de 80 anos, sofreu aumento nestes 20 anos.

A população nas faixas etárias mais elevadas no Rio Grande do Sul vem apresentando uma participação cada vez maior no contingente populacional. A expectativa de vida da população gaúcha passou de 71,1 anos em 1991 para 75,9 anos em 2010, enquanto que a participação dos indivíduos com mais de 65 anos saltou de $5,8 \%$ para 9,3\%. A evolução do índice de envelhecimento da população demonstra esse 
fenômeno ${ }^{5}$. O índice era de 19,4 em 1991, passou dobrou em 2010, indicando que para cada 100 crianças entre 0 e 14 anos, havia 40,7 idosos de 65 anos ou mais de idade. Nesses padrões, o Estado deverá apresentar aproximadamente 2,1 milhões de habitantes com mais de 65 anos e 118,5 idosos para cada 100 crianças em 2030. Assim, enquanto que, em 1991, as crianças e idosos somados representavam 36\% da população gaúcha e os adultos 64\%, em 2010, a proporção é de 30\% e $70 \%$.

Figura 5 - Composição da população total, por gênero e grupos de idade no Rio grande do Sul nos anos 1991, 2000 e 2010

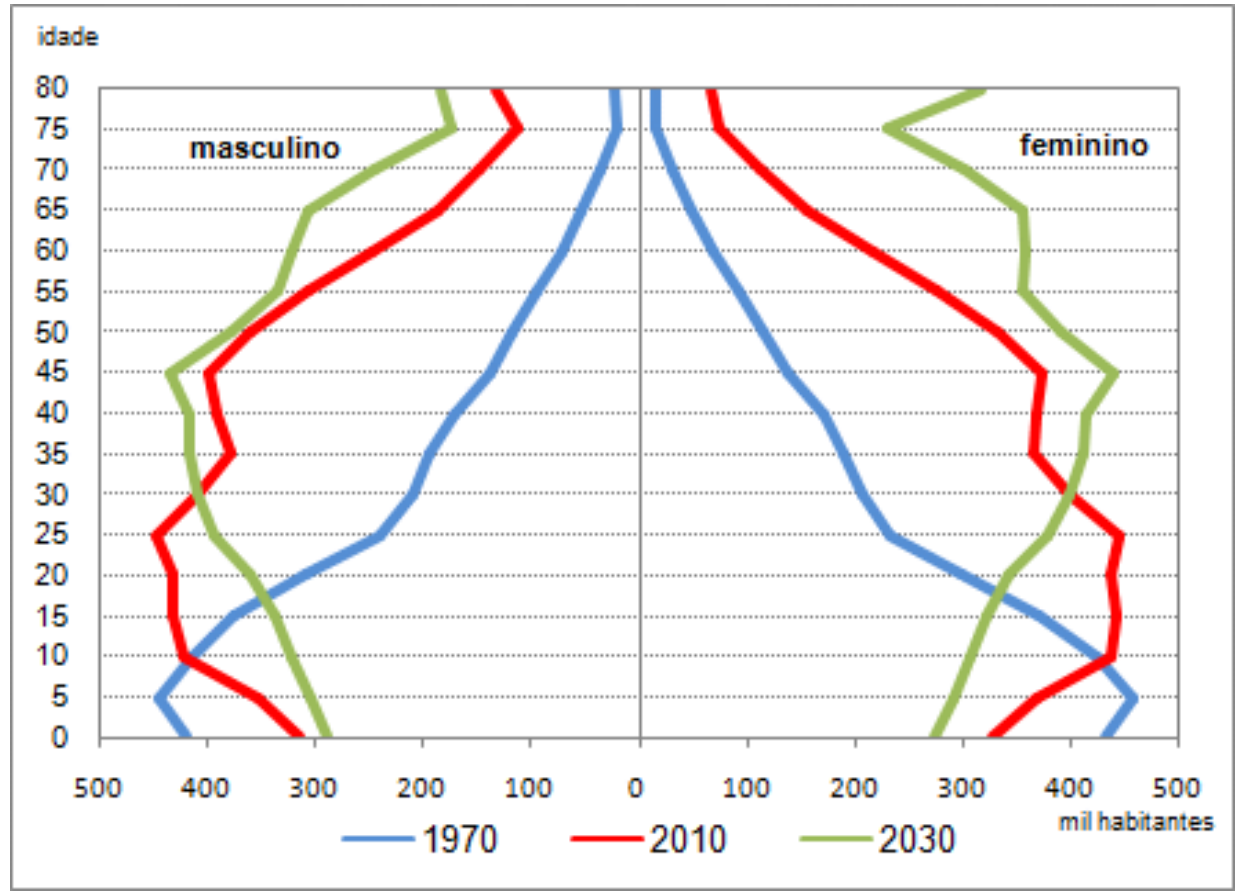

Fonte: IBGE

Se as projeções do IBGE para os próximos decênios se confirmarem, o Rio Grande do Sul já se encontraria no auge desta relação, pois nesta década esta proporção entraria em ascendência, como pode ser observado na Figura 6. Já o Brasil alcançaria esse patamar somente em 2020. Estaríamos, portanto, em vigência ainda de um período que os estudiosos da população denominam de Bônus Demográfico que, de acordo com Jardim (2010), pode ser considerado como o período em que a população ativa (15 a 65 anos) é proporcionalmente mais numerosa que a inativa ( 0 a 14 anos e 65 anos e mais de idade).

\footnotetext{
indivíduos com mais de 65 anos que existem para cada 100 indivíduos com menos de 15 anos.

5 Índice de envelhecimento é a relação entre idosos e jovens de uma população, isto é, o número de 
Figura 6 - Proporção da população inativa no Brasil e Rio Grande do Sul no período 1960 a 2030

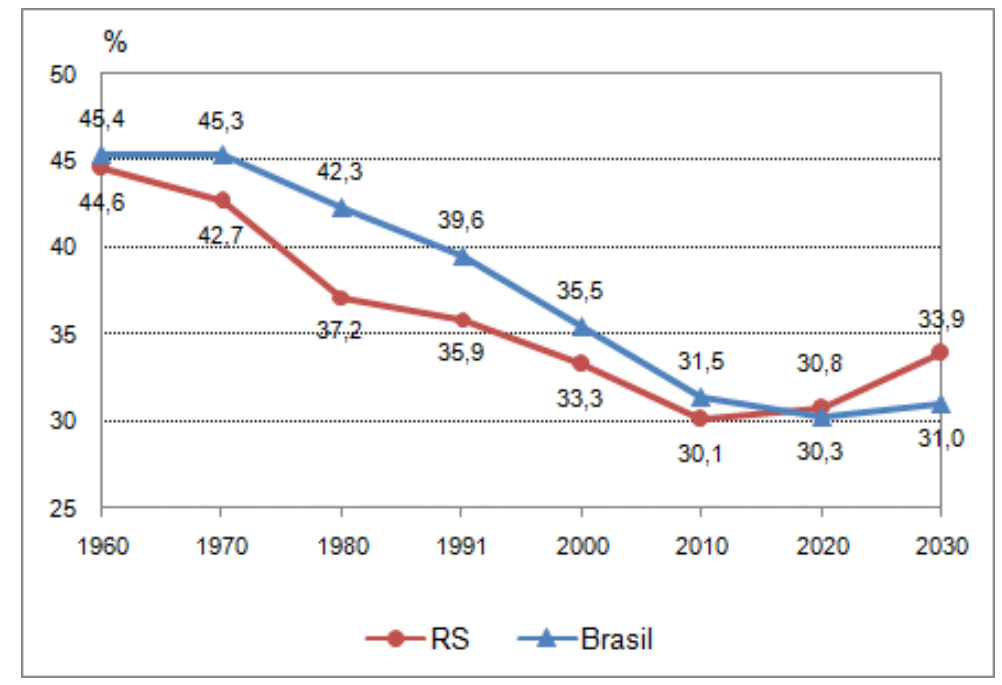

Fonte: IBGE

Esta condição, também defendida pelos estudiosos, indicaria uma vantagem para o desenvolvimento, pois a população funcionaria como uma alavanca para o crescimento social e econômico. Porém, não podemos esquecer que a população mais idosa aumentará em número, o que implicará em enormes desafios à sociedade, principalmente nas questões relativas à saúde e previdência.

\section{Aspectos da qualidade de vida no período 1998-2013}

O Atlas Socioeconômico acompanhou as mudanças no perfil da saúde e educação gaúcha, chamando atenção para determinados aspectos do processo e acompanhando alguns dos principais indicadores - na área da saúde: esperança de vida ao nascer; mortalidade infantil e mortalidade geral; e na área da educação: taxas de alfabetização, atendimento escolar e escolaridade da população com 25 anos ou mais de idade.

Um dos temas mais relevantes na análise da evolução das condições de vida do ponto de vista da saúde é a avaliação da esperança de vida ao nascer. Esse indicador demonstra a melhoria das condições socioeconômicas e ambientais e do nível de qualidade da saúde pública de determinado país ou região e está intimamente relacionado com o acesso ao sistema de saúde local e a adequação deste em responder às necessidades da população. Seu aumento se deve principalmente a alguns fatores como: redução da mortalidade infantil, aumento da cobertura vacinal e melhoria das 
condições sanitárias. O Rio Grande do Sul se destacou durante muitas décadas por ocupar as melhores posições entre os estados brasileiros em relação a estes fatores.

Desde a sua primeira edição, o Atlas Socioeconômico do Rio Grande do Sul destacou que a esperança média de vida ao nascer no Estado, para ambos os sexos, foi sempre superior a brasileira. Em 1991 e 2000 o Estado apresentou nível de esperança de vida que o Brasil iria atingir somente dez anos mais tarde, em 2000 e 2010. Enquanto em 1991 a esperança de vida brasileira era de 64,7 anos, no Rio Grande do Sul a mesma chegava a 68,7 anos. Em 2000, a esperança de vida brasileira atingiu 68,6 anos praticamente o mesmo índice que o Estado havia atingido em 1991, enquanto que no Estado o índice já havia atingido 73,2 anos. Em 2010, quando a esperança de vida brasileira atingiu 73,9 anos - praticamente o mesmo índice do Rio Grande do Sul em 2000, a mesma já alcançava os 75,3 anos (PNUD/IPEA/FJP, 2013).

Em relação ao gênero, estas diferenças ficam ainda mais evidentes com as mulheres apresentando sempre maior esperança de vida ao nascer do que os homens. Como resultado, o número de mulheres nas faixas etárias mais avançadas é hoje significativamente superior ao número de homens. É importante assinalar que o avanço da esperança de vida da população do Estado está também associado à queda da natalidade e da fecundidade e tem como resultado o chamado processo de envelhecimento da população. Por consequiência, já é possível notar a pressão sobre os sistemas previdenciários e de saúde públicos e privados e a intensificação das demandas por serviços especializados, o que acaba por exigir dos gestores públicos o planejamento de políticas públicas de médio e longo prazo.

Quanto à distribuição da esperança de vida ao nascer no território gaúcho, observa-se, desde 1991, uma disposição dos valores superiores à média do Estado, no Eixo Expandido do Nordeste, que se delineia entre Porto Alegre, Caxias do Sul e Passo Fundo. Esse vetor parte da RMPA em direção a Serra e a Produção, estendendo-se rumo ao norte-noroeste e coincide com a região atual de maior desenvolvimento socioeconômico e tecnológico. Da mesma forma, verifica-se também o aumento geral dos níveis de esperança de vida ao nascer em praticamente todo território,em 2010.Em 1991, haviam 238 municípios com índice de esperança de vida acima da média do Estado e,em 2010, este número aumentou para 280 municípios. Já o menor valor médio registrado entre os municípios pulou de 62,40 anos em 1991 para 70,96 anos, em 2010. 
Outro indicador de condições de vida que merece destaque é a mortalidade infantil. Esse indicador é utilizado como um dos mais sensíveis na área de saúde, pois a morte de crianças menores de um ano é resultado de inúmeros fatores de risco que refletem a qualidade dos cuidados pré e pós-natal. Além disso, demonstra a eficácia das políticas públicas em relação às ações de prevenção com a saúde materna e a melhoria das condições socioeconômicas a que a população está submetida. O último Relatório do Fundo das Nações Unidas para a Infância (UNICEF) identificou uma melhora global do indicador nos últimos vinte anos em praticamente todos os países, com destaque para o Brasil, que promoveu uma redução maior do que a média global, embora permaneça alta, segundo os parâmetros da instituição.O Rio Grande do Sul se destacou durante décadas por ocupar, juntamente com Santa Catarina, São Paulo e o Distrito Federal, as melhores posições entre os estados brasileiros em relação ao coeficiente de mortalidade infantil do Brasil.

Nos últimos quinze anos o Atlas demonstrou que o coeficiente de mortalidade infantil no Rio Grande do Sul foi sempre inferior ao brasileiro. Enquanto em 1991 o coeficiente brasileiro era de 44,6 por mil nascidos vivos, no Estado o mesmo era de 22,5 - praticamente a metade. Em 2000, o coeficiente no Brasil atingiu 30,5 por mil nascidos vivos, enquanto que no Estado o coeficiente já era de 16,7. E, em 2010, quando o coeficiente de mortalidade infantil brasileiro atingiu 16,7- praticamente o mesmo índice do RS em 2000, os valores já alcançavam 12,3 por mil nascidos vivos, conforme dados do Atlas de Desenvolvimento Humano 2013. Assim, a queda da mortalidade infantil no Rio Grande do Sul começou mais cedo e foi mais acentuada do que no Brasil por um longo período, diminuindo o seu ritmo em relação ao do país somente nos últimos anos. Como resultado houve uma influência positiva nos índices de esperança de vida ao nascer do Estado.

A sensível diminuição da mortalidade infantil ocorrida no Estado nas últimas décadas atingiu praticamente todo o seu território. Em linhas gerais, pode-se perceber também uma concentração dos menores valores - inferiores à média do Estado, no Eixo Expandido do Nordeste. Em 1991, havia 257 municípios com coeficiente de mortalidade infantil abaixo da média que era de 22,53 óbitos/1.000 nascidos vivos, permanecendo no mesmo patamar, em 2010, quando a média gaúcha foi de 12,38 óbitos/1.000 nascidos vivos. Por outro lado, ainda persiste um número significativo de 
municípios com coeficientes acima da média do Estado que devem ser alvo de políticas públicas mais específicas.Deve-se ressaltar, porém, que a grande maioria dos municípios que apresentam coeficientes de mortalidade infantil muito elevados são municípios com população e número de nascimentos muito baixos sendo, portanto, onde os casos de morte repercutem com mais intensidade nas taxas de mortalidade.

No Rio Grande do Sul, os dois componentes principais do Coeficiente de Mortalidade Infantil - a mortalidade neonatal (até 28 dias após o nascimento) e a mortalidade pós-neonatal (após 29 dias até os 11 meses de idade) estão intimamente ligados a causas específicas. O primeiro resulta de nascimentos de crianças com baixo peso e de condições adversas decorrentes do parto, relacionadas fortemente com a falta de acompanhamento pré-natal adequado. O segundo componente refere-se principalmente às diarréias e infecções respiratórias agudas influenciadas por fatores ambientais, embora o baixo peso ainda possa persistir. Este segundo foi o que mais influiu na diminuição da mortalidade infantil no Rio Grande do Sul até o final dos anos 70 (RIO GRANDE DO SUL/SES, 2010).

Dos anos 80 em diante a mortalidade neonatal que passou a ser mais determinante da queda da mortalidade infantil, através de ações de qualificação do prénatal, expansão do Programa Saúde da Família, promoção do aleitamento materno e de formação dos bancos de leite e a vigilância e da investigação sobre os óbitos infantis, além da redução da gravidez de mães adolescentes e de baixa escolaridade.

Outro aspecto que merece destaque é a Mortalidade Geral, uma das medidas mais utilizadas em saúde pública, que expressa a relação entre o total de óbitos de um determinado local pela população exposta ao risco de morrer. Pode ser considerado um importante indicador, quando associado a mortalidade por grupos de causas, considerando o processo geral de envelhecimento da população brasileira e o aumento da longevidade.

Nesse sentido, o Brasil apresentou importantes mudanças nos quadros de morbidade e mortalidade nos últimos 50 anos, passando de um perfil onde havia a prevalência de problemas típicos de uma população predominantemente jovem para um perfil no qual as notificações de enfermidades crônicas são crescentes, mais próprias de uma população com predomínio das faixas etárias mais avançadas. Segundo a Secretaria da Saúde, essas mudanças se fizeram sentir no Estado de forma mais acentuada, uma 
vez que a proporção de idosos no período foi sempre superior a média brasileira. Vários fatores colaboram para este fato: maior expectativa de vida, queda contínua da mortalidade infantil e da natalidade, melhoria das condições sanitárias e de urbanização, ampla cobertura vacinal e prevenção de doenças por maior acesso aos serviços de saúde. Deste conjunto de fatores resultam uma mais elevada prevalência de fatores de risco, com taxas de morbi-mortalidade e custos crescentes de assistência à saúde decorrente, principalmente, de doenças cardiovasculares, neoplasias, doenças respiratórias crônicas e de causas externas, entre outras.

No Rio Grande do Sul, como pode ser observado no Figura 7, os grupos de causas principais da mortalidade geral para ambos os sexos são: as doenças do aparelho circulatório (30\%); neoplasias ou tumores $(21,27 \%)$; doenças do aparelho respiratório $(11,76 \%)$; causas externas de morbidade e mortalidade $(9,19 \%)$; doenças do aparelho digestivo (4,76\%); doenças endócrinas, nutricionais e metabólicas $(5,50 \%)$ e algumas doenças infecciosas e parasitárias $(4,25 \%)$. E, entre as dez categorias de doenças que mais levam ao óbito estão: o infarto agudo do miocárdio; outras doenças pulmonares obstrutivas crônicas; a neoplasia maligna dos brônquios e dos pulmões; o Diabetes Mellitus; o Acidente Vascular Cerebral; a pneumonia; a insuficiência cardíaca; as causas desconhecidas de morte sem assistência médica; a doença isquêmica do coração e as outras doenças cerebrovasculares.

Considerando a evolução dos grupos de causas principais da mortalidade geral, é importante ressaltar a tendência de queda na categoria das doenças do aparelho circulatório a partir de 1990, embora permaneça com os maiores índices entre as demais. Da mesma forma, chama atenção o aumento exponencial da categoria de neoplasias desde 1970, assim como o aumento a partir do ano 2000, mesmo que em menor proporção, da mortalidade provocada por doenças do aparelho digestivo e doenças endócrinas, nutricionais metabólicas, entre as quais a Diabetes. Por outro lado, a diminuição da participação das causas mal definidas aponta para uma melhora qualitativa dos registros de mortalidade no Rio Grande do Sul. Quanto à distribuição do Coeficiente de Mortalidade Geral entre os municípios, chama atenção a relativa concentração dos índices acima da média de 7,3 óbitos por 1.000 habitantes em 2010, entre os municípios situados no centro e sul do Estado. 
Figura 7 - Evolução da mortalidade geral por grupos de causas principais no Rio Grande do Sul - 1970-2010 (\%)

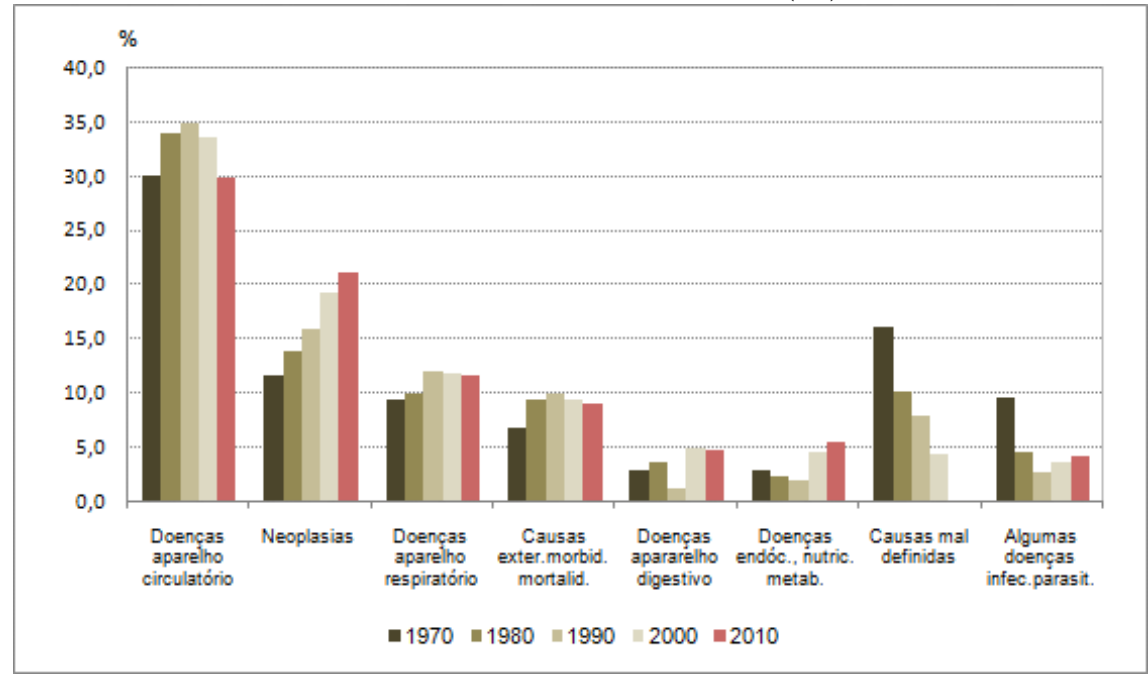

Fonte: SES/DAS. Estatísticas de Saúde 2010

No que se refere a educação, um dos indicadores mais importantes é a alfabetização que promove a inclusão de segmentos da população que se encontram totalmente impedidos de participar autonomamente dos processos econômicos, sociais e culturais que se desenvolvem em seu entorno. O aumento da taxa de alfabetização é, portanto, um indicador de melhoria das condições socioeconômicas e está intimamente relacionado com o acesso e qualidade do sistema de ensino local e a adequação deste em responder às necessidades da população de determinado país ou região. O Rio Grande do Sul se destacou durante muitas décadas por ocupar as melhores posições entre os estados brasileiros em relação à taxa de alfabetização e de atendimento escolar da sua população, o que se refletiu no aumento da média de anos de estudo.

Desde a sua primeira edição, a publicação destacou que a taxa de alfabetização da população de 15 anos ou mais de idade é superior a brasileira e esteve sempre entre as melhores do País. Em 1991, o Estado apresentava taxa de alfabetização que o Brasil iria atingir somente 20 anos mais tarde, em 2010. Enquanto em 1991 a taxa de alfabetização brasileira era de 80,60\%, no Estado a mesma chegava a 90,43\%. Em 2000, a taxa de alfabetização no Brasil atingiu 87,06\%, enquanto que no Rio Grande do Sul o índice já era de 93,72\%. Já em 2010, quando a taxa de alfabetização brasileira atingiu 90,39\% - praticamente o mesmo índice do Estado em 1991, a taxa gaúcha foi de $95,48 \%$.

$\mathrm{Na}$ distribuição territorial, persistem diferenças regionais significativas nas taxas de alfabetização no Estado do Rio Grande do Sul. Embora praticamente todos os 
municípios tenham melhorado seus índices no período, ainda há grande número de municípios com taxas bem inferiores a média do Estado que foi de 95,48\% em 2010. Estes estão concentrados, principalmente, na faixa que abrange porções do centro e do sul do Estado e na faixa norte, abrangendo grande parte das regiões do Alto da Serra do Botucaraí, Rio da Várzea e Médio Alto Uruguai e, mais a oeste, os Coredes Celeiro e Missões.Pode-se perceber também uma concentração dos maiores valores - superiores a média do Estado, no Eixo Expandido do Nordeste.

No que se refere à taxa de atendimento escolar, que identifica o percentual da população de determinada faixa etária que está frequentando a escola, o Estado se destacou durante muitas décadas por ocupar as melhores posições entre os demais estados brasileiros em relação à taxa de atendimento escolar da população de 6 a 14 anos, a qual se aproxima atualmente da universalização. Em relação à taxa de atendimento escolar da população de 15 a 17 anos ocupa hoje uma posição mediana. Já em relação à taxa de atendimento escolar da população de 0 a 5 anos, os dados demonstram que, embora tenha avançado, ainda há muito por fazer no sentido de oferecer um atendimento mais abrangente. Segundo o número de matrículas na préescola por dependência administrativa no período de 1991 a 2010, as redes municipal e particular tiveram um grande incremento, ao contrário da rede estadual, e respondem pelo atendimento quase integral da população matriculada na rede pré-escolar no Estado.

De acordo com os dados, pode-se dizer que, atualmente, $77 \%$ da população de 0 a 3 anos e $42 \%$ da população de 4 a 5 anos não são atendidos por creche e pré-escola. E, entre os 496 municípios do Estado em 2010, somente 16 municípios contam com taxas de atendimento de mais de $50 \%$ na faixa de idade de 0 a 3 anos, chegando até o máximo de $61,82 \%$, sendo que a grande maioria - 350 municípios, contam com menos de $10 \%$ de atendimento do serviço. Já na faixa de idade de 4 a 5 anos, 383 municípios contam com taxas de atendimento de mais de 50\%, sendo que 30 municípios apresentam taxas de atendimento superiores a 90\%, o que demonstra que, atualmente, o atendimento pré-escolar é bem mais abrangente do que o atendimento por creches no Estado. Embora possa ser considerado usual que as crianças de 0 a 3 anos de idade sejam mantidas mais aos cuidados da família, principalmente nos municípios de menor porte, não há como negar que há uma demanda reprimida por atendimento em creche e 
menor em pré-escola, que deve ser solucionada nos próximos anos, conforme prevê a legislação.As Figuras8e 9demonstram a evolução do atendimento escolar da Educação infantil e das matrículas por dependência administrativa no Rio Grande do Sul.

Figura 8 - Taxa de atendimento da Educação Infantil no RS e Brasil em 2000 e 2010

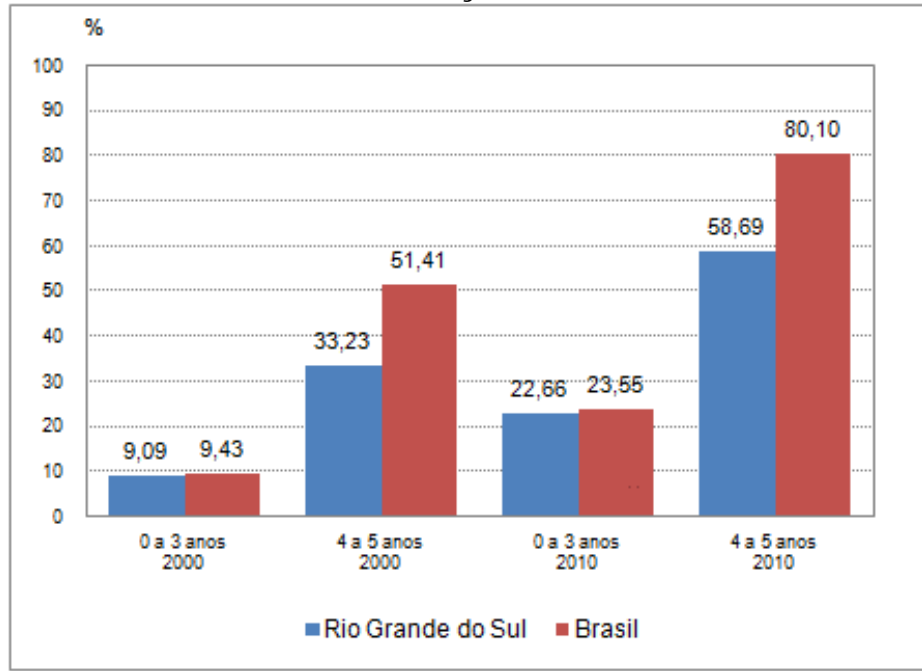

Fonte: Atlas do Desenvolvimento Humano 2013

Figura 9 - Evolução do número de matrículas na Educação Infantil no RS por dependência administrativa 1991, 2000, 2010

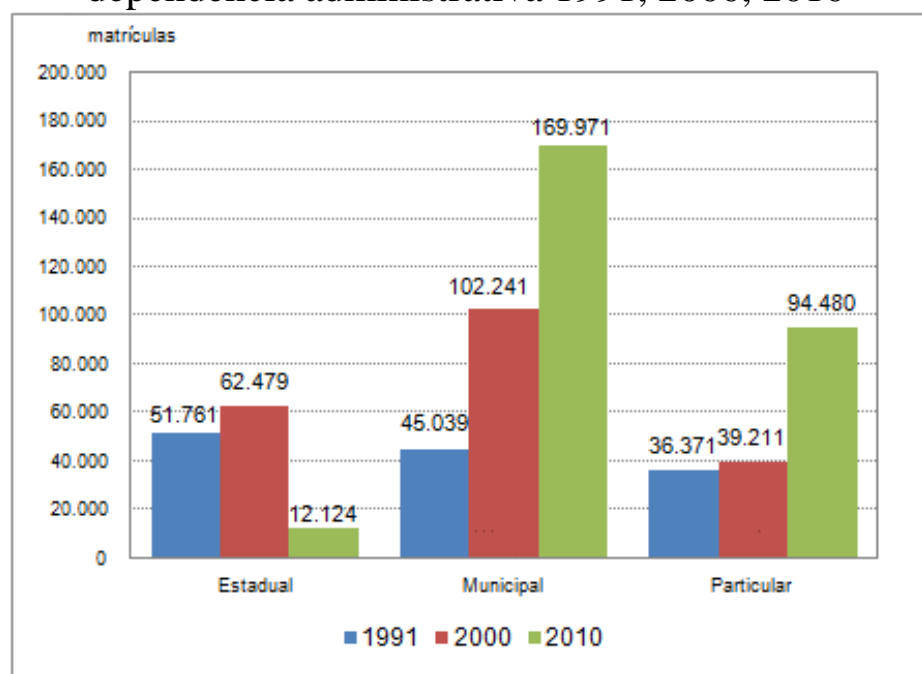

Fonte: FEEDADOS (SE/INEP)

No que se refere à taxa de escolarização ${ }^{6}$ da população de 25 anos ou mais de idade com ensino fundamental completo, no Rio Grande do Sul, houve aumento de 28,7\% em 1991, para 52,1\% em 2010, permanecendo superior a brasileira que é de 50,7\% em 2010. Já a taxa de escolarização da população de 25 anos ou mais de idade

\footnotetext{
${ }^{6}$ A taxa de escolarização diz respeito à proporção entre a população de dada faixa etária que concluiu o ensino fundamental, médio ou superior, em qualquer de suas modalidades, em relação ao total de pessoas da mesma faixa etária.
} 
com ensino médio completo aumentou de 17,6\% em 1991, para 35,4\% em 2010, permanecendo ligeiramente inferior à brasileira que é de $35,8 \%$. No tocante à taxa de escolarização da população de 25 anos ou mais de idade com ensino superior completo registrou-se aumento de 6,1\% para 11,2\% de 1991 a 2010.

Os municípios que apresentam as maiores taxas de escolarização, especialmente os que possuem mais elevados índices de escolaridade da população de 25 anos ou mais de idade, nos três níveis de ensino, também estão concentrados ao longo do Eixo Expandido Porto Alegre-Caxias do Sul-Passo Fundo em 1991, 2000 e 2010. Por outro lado, persistem ao longo dos anos, áreas com índices baixos de escolarização em quase todos os municípios dos COREDEs Sul e Centro Sul; Alto da Serra do Botucaraí e Vale do Taquari; Missões e Vale do Jaguari.

\section{Características da economia gaúcha no período 1998-2013}

O Rio Grande do Sul é atualmente a quarta economia brasileira pelo tamanho do Produto Interno Bruto (PIB), tendo atingido valores de R \$ 296,3 bilhões, conforme as estimativas para o ano de 2012. O Estado participa com 6,7\% do PIB nacional, valores um pouco inferiores aos cerca de $7 \%$ contabilizados no final da década de 90 , sendo superado pelos estados do Rio de Janeiro e Minas Gerais ${ }^{7}$. Convém assinalar que, tanto a posição da economia gaúcha quanto sua participação na economia nacional são fortemente influenciados pela centralidade exercida pela Região Sudeste, com quem a economia gaúcha possui uma associação superior a média brasileira. Além disso, os fortes vínculos com as atividades agroindustriais, com grande ênfase nas exportações de commodities e com outros segmentos exportadores fazem com que os resultados econômicos sofram grande influência das variações da economia global, especialmente da flutuação da taxa de câmbio.

O PIB per capita gaúcho apresentou uma significativa evolução, passando de cerca 10 mil reais, no início dos anos 2000, para 27 mil reais, conforme estimativas para

\footnotetext{
${ }^{7} \mathrm{O}$ posto de primeira economia brasileira entre os estados da federação é ocupado por São Paulo que responde por $33,1 \%$ do PIB nacional, sendo seguido pelo Estado do Rio de Janeiro com 10,8\% e por Minas Gerais 9,3\%. Nos últimos quinze anos, como resultado do processo de desconcentração nacional, São Paulo perdeu cerca de dez pontos percentuais na participação da economia nacional. Como resultado, houve um aumento da participação dos estados do Rio de Janeiro e Minas Gerais e o Rio Grande do Sul passou da segunda para a quarta posição entre as unidades da federação.
} 
2012. Essa ampliação seguiu a tendência nacional, onde os valores foram ampliados de cerca de 8 mil reais para $\mathrm{R} \$ 19,7$ mil reais, em 2010.

Nos últimos quinze anos a estrutura setorial da economia gaúcha manteve suas características principais, com forte participação do setor de serviços que, atualmente abrange cerca de $60 \%$ do Valor Adicionado Bruto (VAB). Além do segmento mais tradicional do comércio, esse setor tem aumentado sua importância principalmente devido a abertura econômica vivenciada nas últimas décadas. Com isso, um número cada vez maior de empresas e empregos tem se instalado no Estado, com destaque para segmentos de serviços de transporte, informação e comunicação, logística, consultoria e manutenção e equipamentos. Também apresenta grande importância no setor de serviços o segmento da administração pública, que ampliou sua participação com base na universalização de serviços como os de saúde e educação.

Embora a estrutura setorial do VAB do Rio Grande do Sul em 2010, confirme a importância do Setor de Serviços no Estado, com o crescimento ocorrido durante as duas últimas décadas, pode-se dizer que a economia gaúcha é impulsionada por dois setores hegemônicos: a agropecuária e a indústria de transformação. Nos últimos quinze anos esses dois segmentos mantiveram sua participação relativamente estável, com leve queda que foi transferida para o setor de serviços.

A Figura 10 demonstra a participação dos setores de atividade na economia do Rio Grande do Sul entre 1998 e 2010. Observa-se que não houve grandes oscilações nos três setores de atividade nesse período. A exceção foi o ano de 2005, quando o setor agropecuário sofreu forte queda $(-17,4 \%)$ devido a uma estiagem de grandes proporções, o que se refletiu na menor participação do setor primário na economia do Rio Grande do Sul, de apenas 7,08\%. O fraco desempenho do setor agropecuário contribuiu para uma queda no PIB do Estado de 2,8\%, em 2005, o que demonstra a importância do setor para a economia gaúcha.

Em 2010, o setor agropecuário gaúcho apresentou uma participação de 8,7\% da estrutura do VAB. Esses números são bem maiores quando associados às atividades agroindustriais $^{8}$. Deve-se ressaltar que o setor agropecuário tem sido fortemente impactado pelas estiagens que, em grande medida, explicam os maus resultados de

\footnotetext{
${ }^{8}$ De acordo Estudo de Desenvolvimento Regional e Logística do RS (Rumos 2015, se somadas as atividades agroindustriais, esta participação chega a $30 \%$ da estrutura econômica, além de ser o setor econômico mais desconcentrado no território (RIO GRANDE DO SUL/SCP, 2006).
}

Geo UERJ - Ano 15, n' ${ }^{\circ}$ 24, v. 2, $2^{\circ}$ semestre de 2013

ISSN: 1415-7543 E-ISSN: 1981-9021

http://www.e-publicacoes.uerj.br/index.php/geouerj 
algumas safras e impactam negativamente no PIB, como no caso dos anos de 2004 e 2005. Esse condicionante tende a se repetir para o ano de 2012, quando o Estado teve problemas com a irregularidade das precipitações, especialmente no período de verão.

Figura 10- Participação dos setores de atividade no Valor Adicionado Bruto do Rio Grande do Sul (1998-2010)

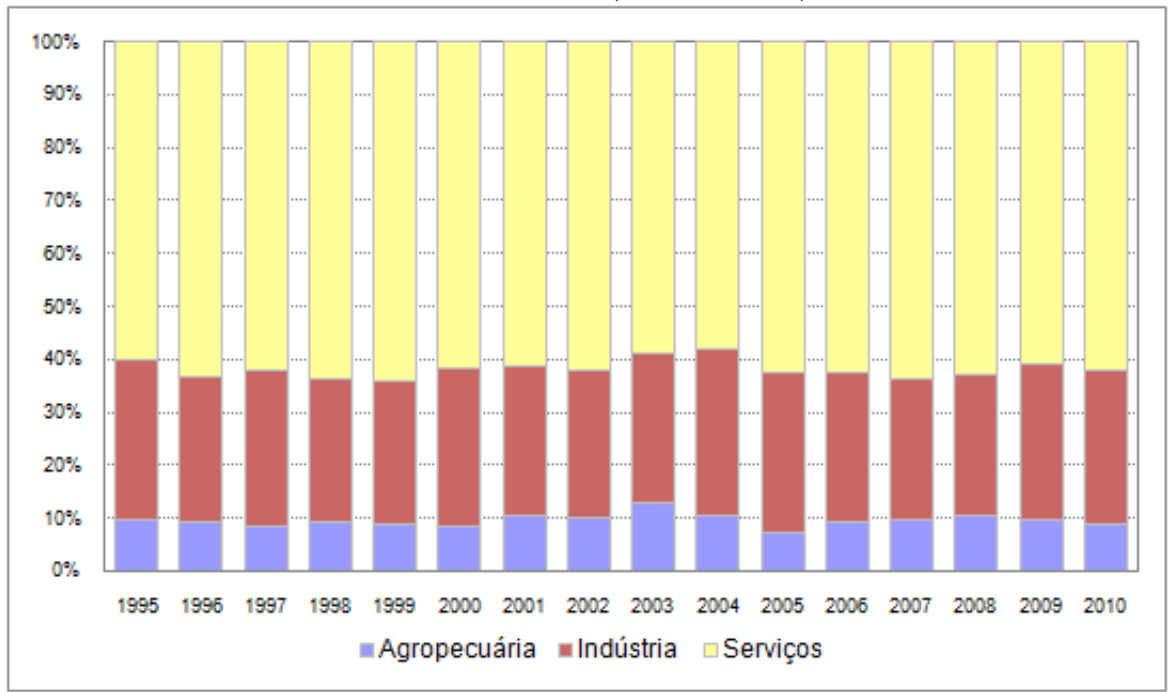

Fonte: Fundação de Economia e Estatística (FEE)

A indústria responde por cerca de $29 \%$ da economia gaúcha, sendo que desta participação a responsabilidade da indústria de transformação é de $21 \%$. A indústria extrativista possui uma participação pouco expressiva dentro da economia estadual menos de $1 \%$ do VAB e as indústrias gaúchas dedicadas à extração mineral constituemse, majoritariamente, de extração de minerais não-metálicos.

$\mathrm{Na}$ indústria de transformação o Estado apresenta uma quantidade diversificada de segmentos que se desenvolveram a partir das agroindústrias e de outros segmentos ligados ao setor primário e, posteriormente, foram agregados novos segmentos. $\mathrm{Na}$ matriz industrial destacam-se os segmentos agroindustrial, que inclui as indústrias de alimentos, bebidas e as que utilizam insumos agrícolas; o complexo coureiro-calçadista; o complexo químico; e o complexo metal-mecânico. Atualmente a indústria de transformação ocupa a terceira posição no parque nacional (depois de São Paulo e Minas Gerais), com uma participação em torno de $9 \%$.

Os principais gêneros são os setores de mecânica, material de transporte, química, o mobiliário,vestuário e calçados, todos com vínculos com o mercado exportador. Esse vínculo pode ser constatado nos índices de crescimento do setor industrial gaúcho após a desvalorização cambial do plano real, quando estes setores que 
vão apresentar o maior dinamismo, pela melhora da sua relação de competitividade com o exterior.

Os segmentos ligados ao mercado exportador possuem também um alto grau de concentração espacial de sua produção. O Eixo Expandido Porto Alegre- Caxias do Sul - Passo Fundo, polariza estes segmentos produtivos em sua grande parte. Apesar de bastante concentrada espacialmente, alguns segmentos, como o de produtos alimentares, apresentam um grau de dispersão maior pelo território gaúcho.

No que se refere ao setor exportador, convém assinalar que, em 1998, ano da primeira edição do Atlas Socioeconômico do Rio Grande do Sul, o Brasil experienciava um período de abertura econômica, visando a uma inserção competitiva do país no processo de globalização. Essa abertura comercial, conjugada à valorização da taxa de câmbio, ancorada ao dólar, e ao desmonte dos mecanismos de proteção tarifários e não tarifários, gerou um baixo crescimento das exportações e aumento considerável das importações brasileiras, ao mesmo tempo em que essa política contribuía para a estabilização dos preços internos (BELLO, 2004, p.297).

O Rio Grande do Sul, por apresentar uma economia com grande influência do setor exportador, baseada em empresas de menor porte que desenvolvem suas atividades com menores requisitos tecnológicos, foi significativamente afetado pela abertura econômica e pela valorização da moeda. Alguns segmentos da indústria gaúcha, tais como vestuário, calçados e produtos alimentares, foram os mais afetados pela política econômica brasileira ${ }^{9}$. É nesse período que o Rio Grande do Sul procura se inserir no processo de abertura econômica do Brasil através da atração de novos investimentos, cujos maiores exemplos foram a instalação de uma unidade da montadora da General Motors e da fábrica da Dell.

A desvalorização da moeda brasileira ocorrida em janeiro de 1999 trouxe novas possibilidades às exportações do Rio Grande do Sul, principalmente nos setores da agroindústria e outros voltados ao mercado externo. A vinculação da economia gaúcha com a agropecuária, que passou a apresentar forte crescimento, levou a uma recuperação econômica mais rápida em relação à economia brasileira. Essa recuperação se refletiu no aumento dos níveis de produção, emprego e da participação da economia do Rio Grande do Sul na economia brasileira, no período 1999-2002.

\footnotetext{
${ }^{9}$ Para uma discussão mais aprofundada sobre o tema, consultar Calandro e Campos (2004).

Geo UERJ - Ano 15, nº 24, v. 2, $2^{\circ}$ semestre de 2013

ISSN: 1415-7543 E-ISSN: 1981-9021

http://www.e-publicacoes.uerj.br/index.php/geouerj
} 
A partir de 2005, ocorreu uma nova valorização do câmbio e expansão do comércio internacional brasileiro. O câmbio valorizado trouxe novas dificuldades para a economia gaúcha, principalmente para o setor de calçados, que passou a concorrer com o baixo preço dos produtos chineses e vietnamitas. A participação da economia gaúcha no Brasil sofreu queda significativa no ano de 2005, principalmente em decorrência da estiagem daquele ano, quando passou a se estabilizar entre $6,6 \%$ e 6,7\% até o ano de 2012, não recuperando a participação que teve entre os anos de 1999 e 2002.

No período 1998-2012, a economia do Rio Grande do Sul apresentou retração do Produto Interno Bruto nos anos de 1998 (-0,9\%), 2005 (-2,8\%), 2009 (-0,4\%) e 2012 $\left(-1,8 \%^{10}\right)$. Nesses quatro anos, o Produto Interno Bruto do Estado acompanhou o desempenho negativo da economia brasileira nos anos de 1998, quando o Brasil cresceu apenas 0,1\%; em 2009, com a retração do PIB do Brasil de 0,6\%; e em 2012, quando o PIB brasileiro cresceu apenas 0,9\% (CEPAL, 2013). O ano de 2005 foi o único em que a economia gaúcha não seguiu o desempenho de crescimento da economia brasileira ${ }^{11}$, devido ao fraco desempenho do setor agropecuário gaúcho.Os anos de 2004 e 2008, muito afetados pelas estiagens, apresentaram crescimento inferior ao brasileiro.

$\mathrm{O}$ ano de 2012, quando a economia do Estado teve desempenho de $-1,8 \%$, também foi marcado por uma grande estiagem que diminuiu em $27 \%$ as exportações de soja para a China e se refletiu no setor industrial. Também foi influenciado pela queda na demanda mundial pelos produtos gaúchos com a crise econômica corrente, e pelos embargos impostos pela Argentina, principalmente aos calçados, máquinas, equipamentos e produtos químicos, e pela Rússia, às carnes bovina, suína e de frango. $\mathrm{O}$ único setor cujo desempenho foi consideravelmente positivo em 2012 foi o do fumo, da indústria de transformação, consequência da demanda da China e dos Estados Unidos. No entanto, os impactos da estiagem de 2012 na economia gaúcha não foram tão intensos como em 2005, devido à manutenção dos preços agrícolas no ano mais recente (CALDAS, 2013, p.53).

A grande safra agrícola de soja 2012-2013, somada a recuperação do setor da agroindústria e ao desenvolvimento de novos segmentos indicam a recuperação do PIB

\footnotetext{
${ }^{10}$ Estimativas preliminares.

${ }^{11}$ O estudo RS 2010, produzido em 1998, apontava a mesma tendência de acompanhamento da economia do Rio Grande do Sul em relação à nacional entre os anos de 1985 e 1995 (RIO GRANDE DO SUL, 1998, p.11).
} 
gaúcho para o ano de 2013 e, conforme os dados preliminares, seu crescimento deve ficar acima da média nacional.

Considerando esses aspectos, aponta-se a importância das exportações do Rio Grande do Sul para sua economia e suas contas públicas. Nos últimos quinze anos, a economia do Rio Grande do Sul vem apresentando oscilações em sua participação nas exportações da economia brasileira. Nesse período, o Estado chegou a ter a segunda maior participação (Valor em US\$ FreeOnBoard) nas exportações do Brasil, em 2003, com 10,97\%, e em 2012, é a quinta maior economia exportadora dentre os Estados brasileiros, com $7,17 \%$.

Nos últimos quinze anos, pode-se também observar mudanças nos parceiros comerciais do Rio Grande do Sul. O principal destino das exportações do Rio Grande do Sul deixou de ser os Estados Unidos para ser a China, refletindo a ascensão do país asiático no presente século. Em 1999, os Estados Unidos representavam 25,52\% das exportações do Estado, seguidos pela Argentina, com 11,42\%. A China representava, em 1999, apenas 1,72\% das exportações do Rio Grande do Sul. Em 2002, ano da segunda edição do Atlas, os Estados Unidos compravam 28,51\% das exportações do Rio Grande do Sul, a China já representava 6,97\% das exportações do Estado e a Argentina, em crise econômica, apenas 3,3\%. Em 2011, o principal comprador do Rio Grande do Sul já era a China, com 17,4\% das exportações do Estado, seguida por Argentina, com 10,2\% e Estados Unidos, com 7,1\% (BRASIL, 2013),

A Figura 11 demonstra a participação dos três países mais importantes nas exportações do Rio Grande do Sul, no período 1999-2012. A maior participação da China nas exportações se apresenta coerente com os dados para o Brasil, que tem nos Estados Unidos o segundo maior comprador, seguidos pela Argentina. Em 1999, o MERCOSUL era o destino de 17,48\% das exportações do Rio Grande do Sul, em 2002, se reduziu a $6,35 \%$ e, em 2011, era de $15,93 \%$. A crise do MERCOSUL no período 1999-2002, com crises econômicas na Argentina, em 2001, e no Uruguai, em 2002, se refletiu na exportações do Rio Grande do Sul para os países do bloco, o que levou o Estado a procurar novos mercados para seus produtos. 
Figura 11 - Participação (\%) de China, Estados Unidos e Argentina nas exportações do Rio Grande do Sul (1999-2012)

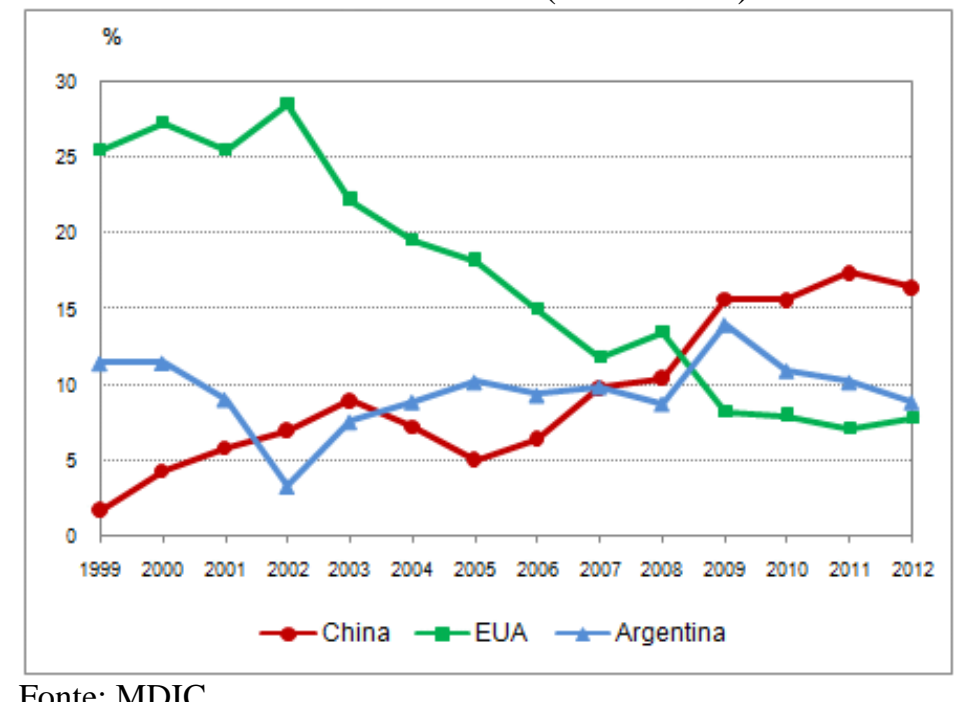

Em relação às importações, no ano de 1999, a Argentina era a origem de $28,73 \%$ da compra de produtos estrangeiros do Rio Grande do Sul, seguida pelos Estados Unidos (17,83\%), Uruguai (6,17\%), Argélia (5,85\%) e Alemanha (5,35\%). No ano de 2002, quando da segunda edição do Atlas Socioeconômico do Rio Grande do Sul, a Argentina seguia sendo o país que mais exportava para o Rio Grande do Sul $(23,63 \%)$, seguida por Estados Unidos $(13,01 \%)$, Nigéria $(11,81 \%)$, Argélia $(7,52 \%)$ e Alemanha (7,37\%). No ano de 2011, a Argentina havia aumentado ainda mais sua participação nos produtos vendidos ao Estado, com 25,9\%, seguida pela Nigéria (14\%), Argélia (9,8\%), Estados Unidos (6,7\%) e China (6,4\%) (BRASIL, 2013).

Nesse período, a Argentina se manteve como principal vendedora de produtos ao Rio Grande do Sul, enquanto a Nigéria e a China apresentaram crescimento constante e os Estados Unidos forte queda na participação das importações do Estado. No caso do Brasil, a origem das principais importações são China, Estados Unidos e Argentina. O MERCOSUL, em 1999, era a origem de 35,06\% das importações do Rio Grande do Sul, em 2002, era de 28,25\% e, em 2011, de 28\% (BRASIL, 2013).

Resumidamente, pode-se afirmar que, nesse período de quinze anos, a China passa a possuir cada vez mais espaço na economia gaúcha, constituindo-se como principal compradora dos produtos do Rio Grande do Sul e aumentando substancialmente a venda de seus produtos ao Estado. Ao mesmo tempo, observa-se a diminuição da participação dos Estados Unidos tanto nas exportações quanto nas importações gaúchas. A Argentina possui um espaço mais destacado no intercâmbio 
com o Rio Grande do Sul em relação a seu comércio com o Brasil, constituindo-se como a principal vendedora de produtos ao Estado, enquanto no caso da economia brasileira, a Argentina se apresenta como terceiro país de origem das importações do Brasil.

O desempenho das exportações do Estado tem fortes vínculos com o comportamento do setor primário da economia. No que se refere à participação setorial na economia do Estado, entre 1998 e 2010 os setores da agropecuária, indústria e serviços apresentaram participação relativamente constante.

No que se refere à agropecuária, o cultivo da soja foi um dos que teve maior expansão territorial no Rio Grande do Sul nesse período. A demanda pelo produto aumentou ao mesmo tempo em que a China se constituiu como sua principal compradora. Como exemplo, em 2012, a China comprou 86,6\% da soja exportada pelo Rio Grande do Sul. Quando consideramos Taiwan como destino chinês, o percentual alcançou 94\% (CALDAS, 2013, p.54).

A produção de soja, que ainda tem sua maior concentração nas regiões dos COREDEs Rio da Várzea, Noroeste Colonial e Alto Jacuí, principalmente nos municípios de Palmeira das Missões, Cruz Alta, Santa Bárbara do Sul e Tupanciretã, sofreu expansão em direção ao sul do Estado. Nesse período, a produção de soja do Rio Grande do Sul teve um aumento de 5.237.840 de toneladas (média entre os anos 19982000) para 10.074.299 toneladas (média entre os anos 2009-2011), crescimento inferior ao brasileiro, que mais que dobrou sua produção nesses anos, de 31.705 .247 de toneladas para 66.972.391 de toneladas. A concorrência com a soja produzida em outros Estados, como Mato Grosso e Paraná, com maiores vantagens na produção, pode explicar a menor produtividade do Rio Grande do Sul. As Figuras 12 e 13 indicam a expansão territorial da produção de soja em direção ao sul do Estado. 
O desempenho das exportações do Estado tem apresentado reflexos sobre a balança comercial e as contas públicas do Rio Grande do Sul. De forma geral, pode-se afirmar que as exportações gaúchas possuem grandes vínculos com as atividades agropecuárias e agroindustriais. A demanda da China pela soja do Estado tem sido uma das grandes responsáveis pela expansão desse produto no período 1998-2013

Figura 12 - Quantidade produzida de soja em grão no RS, média 1998 - 2000

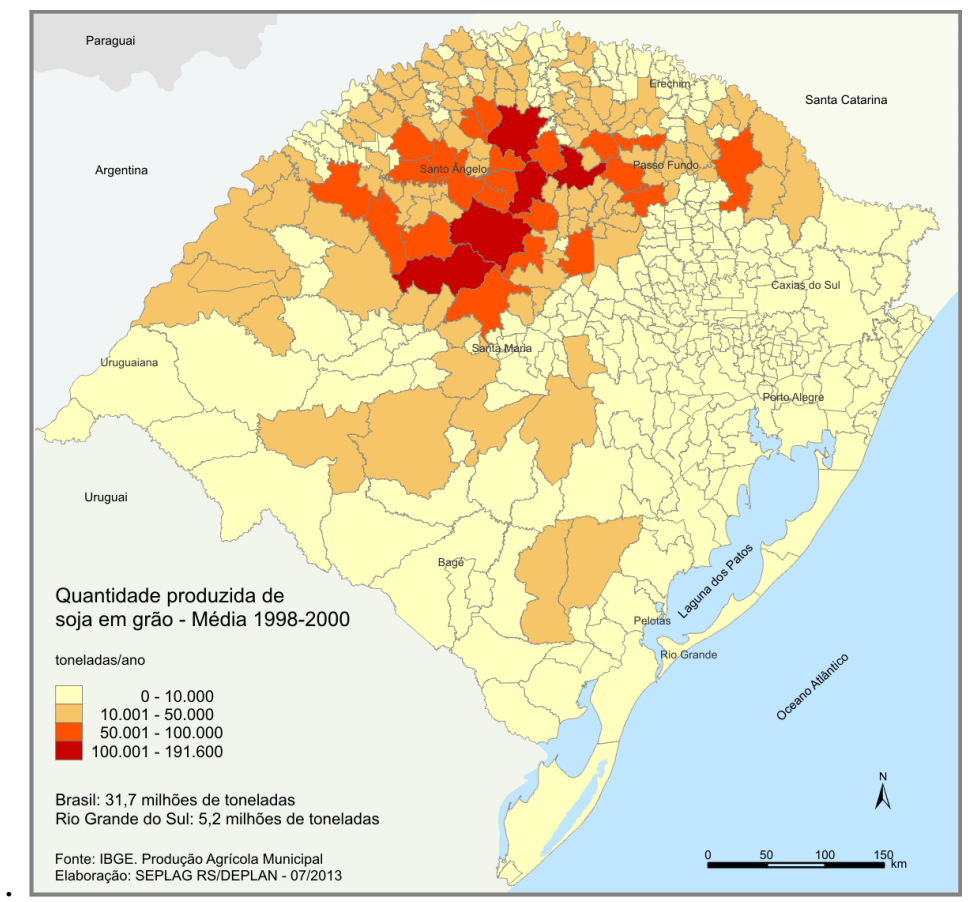


Figura 13 - Quantidade produzida de soja em grão no RS, média 2009 - 2011

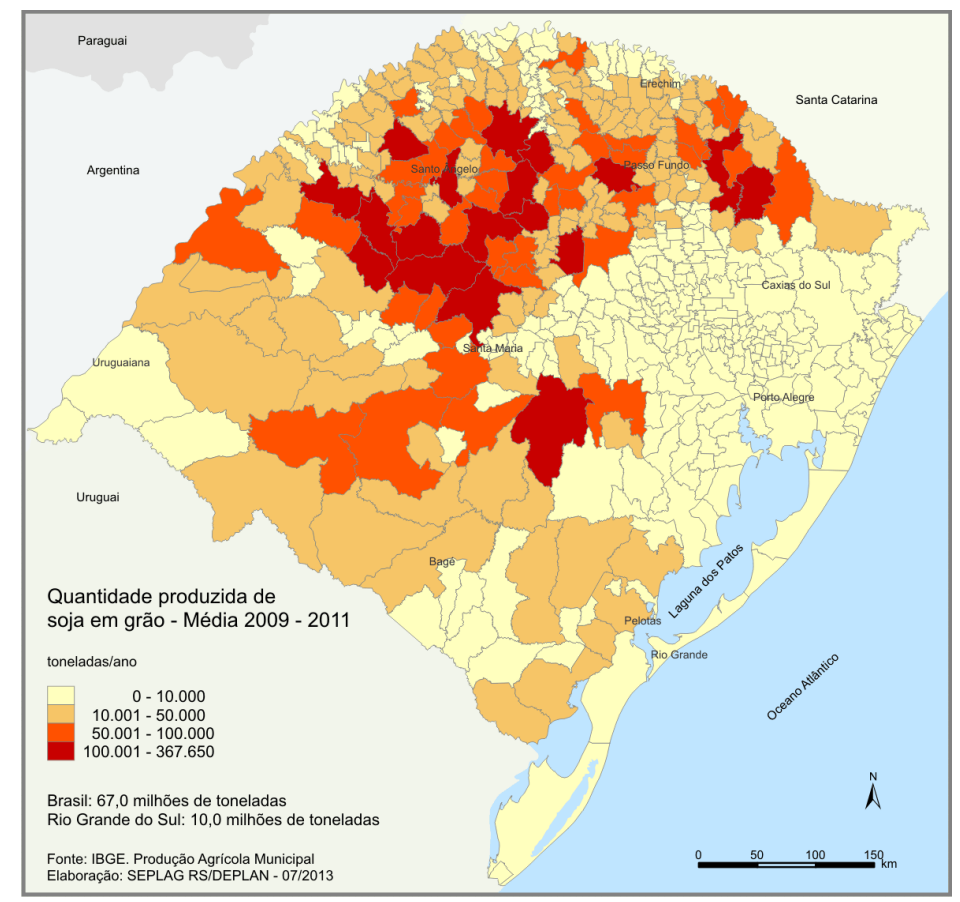

Entretanto, pode-se afirmar que alguns itens de nossa pauta de exportações e de importações vêm sendo positivamente influenciados pelo desenvolvimento de segmentos industriais existentes e novos, que vem incorporando novas tecnologias e processos ao parque industrial gaúcho. É o caso da indústria vinculada ao polo naval, ao segmento metal-mecânico, de máquinas e implementos agrícolas, energia eólica e petróleo e gás. O resultado logo passará a ser observado na balança comercial, onde já figuram resultados da exportação de plataformas de petróleo, carrocerias e equipamentos para a industria de energia eólica.

\section{Considerações finais}

O Atlas Socioeconômico do RS tem se afirmado nos último quinze anos como uma ferramenta diferenciada para conhecimento e análise territorial no Estado do Rio Grande do Sul. A publicação distingue-se por selecionar dados brutos e indicadores que possibilitam uma visão abrangente sobre o Estado, em seus aspectos históricos e geográficos, de meio ambiente, infraestrutura, dos indicadores sociais e da economia. A importância da ferramenta pode ser verificada pela sua ampla utilização como base para elaboração de políticas públicas, pelas citações de referências de pesquisadores e pela utilização nos diferentes níveis de ensino. 
Desde sua primeira edição impressa o Atlas vem qualificando o seu conteúdo na forma de textos, gráficos e mapas e facilitando a sua disseminação através da disponibilização em meio digital. Esse trabalho foi facilitado pela disseminação de novas plataformas de dados disponibilizadas pelos diferentes institutos de pesquisa primária e pela proliferação dos sistemas de informação geográfica que se tornaram de mais fácil operabilidade, utilizando diferentes formatos de dados espaciais.

No que tange à demografia, o artigo constatou o avanço da transição demográfica iniciada no final da década de 70, traduzida na queda da fecundidade e da mortalidade, na drástica redução do crescimento vegetativo e na urbanização crescente. Como resultado temos atualmente um perfil de população diferenciado, que pode ser verificado através da análise da pirâmide etárias, cuja trajetória indica um processo contínuo de envelhecimento da nossa população que tende a levar a um crescimento vegetativo cada vez menor. O Rio Grande do Sul vivencia o bônus demográfico com grande volume de população ativa, fenômeno que coloca para o futuro o desafio de lidar com um Estado cada vez mais envelhecido, com efeitos sobre o mercado de trabalho e o sistema educacional, de saúde e previdenciário.

Essas transformações no perfil demográfico da população são também resultado de avanços na área da saúde que contribuíram para a melhoria da área de diagnóstico e prevenção e tratamento de doenças. Por outro lado, o processo de envelhecimento da população e a sua urbanização crescente desafiam o sistema de saúde a lidar com um perfil de doenças cada vez mais complexo e gera uma maior pressão sobre o sistema de saúde.

Da mesma forma, na educação houve aumento significativo dos índices de alfabetização e das taxas de atendimento escolar referentes aos três níveis de ensino fundamental, médio e superior, que colaboraram para o aumento da escolaridade geral da população. Os desafios se colocam em relação à qualificação do ensino nos diferentes níveis e em relação ao atendimento escolar da população de 0 a 5 anos, onde há uma demanda reprimida por atendimento.

No que se refere à dinâmica das atividades econômicas, observou-se que o Estado tem acompanhado o processo de desenvolvimento brasileiro, apresentando alterações mais significativas como resultado de eventos excepcionais, como os resultantes do desequilíbrio na balança comercial, medidas protecionistas adotadas pelos 
países importadores, eventos de estiagens periódicas ou safras acima da média. Assim, em que pese a grande participação do setor de serviços, a economia do Estado é significativamente afetada pela dinâmica do setor agropecuário e da indústria de transformação.

Nos últimos quinze anos, o parque industrial gaúcho foi complementado com a inserção de novos segmentos, como o automotivo, que contribuiu significativamente para a ampliação do segmento metal-mecânico. Esse segmento deverá ser impulsionado com os resultados futuros do polo naval, recentemente instalado em Rio Grande. Do ponto de vista das exportações observou-se uma tendência geral de recuperação, como resultado do aumento equilíbrio da balança comercial e da ampliação de novos segmentos.

Por último, convém assinalar, no que tange à distribuição territorial, que ainda persistem no território gaúcho diferenças regionais significativas resultantes da concentração da população e do desenvolvimento. Por um lado, um grande número de municípios situados ao longo do Eixo Expandido Porto Alegre-Caxias do Sul-Passo Fundo destacam-se por reunir atividades econômicas e apresentarem os melhores indicadores sociais e, por outro, uma grande parcela de nosso território, principalmente situada em um arco ao longo de nossa faixa de fronteira, enfrenta problemas econômicos que se refletem no empobrecimento de sua população e no esvaziamento demográfico dessas áreas.

\section{Referências}

BELLO, T. da S.. O comércio externo brasileiro e o gaúcho e o Plano Real. Indicadores Econômicos FEE, v.32, n.2. 2004. p.295-331.

BRASIL. MINISTÉRIO DO DESENVOLVIMENTO, INDÚSTRIA E COMÉRCIO EXTERIOR (MDIC). Balança comercial por unidade da federação. 2013. Acesso em: 05 de agosto de $2013 . \quad$ Disponível em: <http://www.mdic.gov.br//sitio/interna/interna.php?area=5\&menu=1076>.

BANDEIRA, M. D.. Uma visão demográfica do Estado do Rio Grande do Sul no contexto brasileiro: análise dos principais indicadores demográficos. In: CONCEIÇÃO, Octávio A. C. et al. (Org.). A evolução social.Porto Alegre: FEE, 2010. (Três décadas de economia gaúcha, 3 ).

CALANDRO, M. L.; CAMPOS, S. H.. Dez anos de Plano Real e a indústria gaúcha. Indicadores Econômicos FEE, v.32, n.2. 2004. p. 247-273.

CALDAS, B. B.. O desempenho das exportações gaúchas em 2012. Indicadores Econômicos FEE, v.40, n.4. 2013. p.51-60. 
COMISIÓN ECONÓMICA PARA AMÉRICA LATINA Y EL CARIBE(CEPAL). CEPALSTAT: bases de dados. Acesso em: 05 de agosto de 2013. Disponível em: $<$ http://interwp.cepal.org/sisgen/ConsultaIntegrada.asp?IdAplicacion=6\&idTema=131\& idIndicador $=2204 \&$ idioma $=\mathrm{e}>$.

JARDIM, M. de L. T.. Tendências demográficas e perspectivas futuras da população gaúcha. In: CONCEIÇÃO, Octávio A. C. et al. (Org.).A evolução social.Porto Alegre: FEE, 2010. (Três décadas de economia gaúcha, 3).

PROGRAMA DAS NAÇÕES UNIDAS PARA O DESENVOLVIMENTO (PNUD); INSTITUTO DE PESQUISAS ECONÔMICAS APLICADAS (IPEA); FUNDAÇÃO JOÃO PINHEIRO (FJP). Atlas do Desenvolvimento Humano no Brasil - 2013. Disponível em: http://www.atlasbrasil.org.br/2013/. Acessado em 23 de setembro de 2013.

RIO GRANDE DO SUL. SECRETARIA DA COORDENAÇÃO E PLANEJAMENTO (SCP). Atlas Socioeconômico do Estado do Rio Grande do Sul. Porto Alegre, 1998.

Atlas Socioeconômico do Estado do Rio Grande do Sul - $2^{\mathbf{a}}$ edição. Porto Alegre, 2002.

Estudo de Desenvolvimento Regional e Logística para o Estado do Rio Grande do Sul - Rumos 2015 (volumes 1, 2 3, 4, 5 e Relatório Síntese). Porto Alegre, 2006.

RIO GRANDE DO SUL. SECRETARIA ESTADUAL DA SAÚDE (SES). A saúde da população do Estado do Rio Grande do Sul, 2015. Porto Alegre, $1^{\text {a }}$ Ed., 2006.

Artigo recebido para publicação em junho de 2013.

Artigo aceito para publicação em julho de 2013. 